\title{
Reducing the Levels of Sodium, Saturated Animal Fat, and Nitrite in Dry-Cured Pork Meat Products: A Major Challenge
}

\author{
Hassan Safa, Stéphane Portanguen, Pierre-Sylvain Mirade \\ QuaPA, INRA, St-Genès-Champanelle, France \\ Email: pierre-sylvain.mirade@inra.fr
}

How to cite this paper: Safa, H., Portanguen, S. and Mirade, P.-S. (2017) Reducing the Levels of Sodium, Saturated Animal Fat, and Nitrite in Dry-Cured Pork Meat Products: A Major Challenge. Food and $\mathrm{Nu}$ trition Sciences, 8, 419-443.

https://doi.org/10.4236/fns.2017.84029

Received: March 1, 2017

Accepted: April 24, 2017

Published: April 27, 2017

Copyright ( 92017 by authors and Scientific Research Publishing Inc. This work is licensed under the Creative Commons Attribution International License (CC BY 4.0).

http://creativecommons.org/licenses/by/4.0/

\begin{abstract}
The curing of meat is a conservation technique widely used since ancient times to prolong shelf-life. It consists in exposing meat to a mixture of sodium chloride and nitrate/nitrite. Sodium chloride affects the flavor, texture and shelf-life of meat products. Animal fat mainly affects the flavor and texture, and nitrate and nitrite affect the color and flavor, and give cured meat products their typical aroma. Excessive intake of sodium has been linked to arterial hypertension and increased risk of cardiovascular diseases. Excessive intakes of saturated fatty acids in pork fat, and also of nitrite, have been identified as factors promoting some cancers. There is consequently an increasing consumer demand to reduce these ingredients in processed meat and so develop healthier cured meat products. This paper reviews how and to what extent sodium, animal fat rich in saturated fatty acids, and nitrite contents can be reduced in the production of dry-cured hams and dry-fermented sausages.
\end{abstract}

\section{Keywords}

Sodium, Saturated Fatty Acids, Nitrite, Dry-Fermented Sausage, Dry-Cured Ham

\section{Introduction}

Since ancient times, the widespread curing of pork products such as dry-fermented sausages and dry-cured hams has been used as a conservation method to extend the storage life of pork meat. The method consists in placing in contact whole muscles (ham) or mixtures of chopped lean meat and fat (sausage), with a salting mixture, often made up of sodium chloride ( $\mathrm{NaCl}$, hereafter "salt"), potassium nitrite or sodium nitrite $\left(\mathrm{KNO}_{2}\right.$ or $\mathrm{NaNO}_{2}$, food preservatives E249 or E250, hereafter "nitrite"), and sodium nitrate or potassium nitrate $\left(\mathrm{NaNO}_{3}\right.$ or 
$\mathrm{KNO}_{3}$, food preservatives E251 or E252, hereafter "nitrate”). The salting mixture preserves the food product from all microbiological spoilage by the barrier effect it induces through lowering water activity $\left(a_{\mathrm{w}}\right)$ [1]. It also contributes positively to the final organoleptic qualities of the dried/cured product, such as its color, texture, flavor and aroma. In the case of dry-fermented sausage the salting step is followed by a fermentation step, which causes $\mathrm{pH}$ to fall; ham undergoes a resting step at low temperature $\left(2^{\circ} \mathrm{C}-4^{\circ} \mathrm{C}\right)$, which allows homogenization of the salt. In both cases, there is then a drying and ripening step that allows the development of the typical aroma of this type of meat product. The pork dry-curing process varies according to geographical region, including within Europe [2]. In northern Europe, dried-cured pork products are made with short ripening times, are treated with only salt and nitrite, and usually undergo a smoking step. By contrast, in Mediterranean countries, the drying/ripening times are much longer, the salting mixture is composed of salt and nitrate/nitrite, and no smoking is performed. The final organoleptic and sensory qualities of dried-cured pork products therefore depend not only on the qualities of the raw materials and the ingredients or additives used in the formulation, but also on the various traditional production processes used in different parts of the world [3].

From a nutritional point of view, the consumption of dried-cured pork products should remain moderate, as their high salt and fat contents carry a large quantity of sodium (second-ranking source after cereal and bakery products), cholesterol, saturated fatty acids and calories into the diet. For example, final salt content reaches $5 \%$ in dry-fermented sausage, and fat content is usually in the range 30\% - 50\% [4]. In dry-cured Spanish serrano ham, salt content expressed relative to dry matter is between $8 \%$ and $15 \%$ at the end of drying/ripening [5]. It is clearly established that excessive consumption of sodium in the diet favors arterial hypertension and increases the risk of heart attack, osteoporosis [6] [7], gastric cancer [8], and kidney disease [9]. Numerous studies have shown that in European and Northern American countries, about 75\% - 85\% of sodium intake is attributable to industrially-manufactured food products and foods eaten away from the home, against $10 \%-15 \%$ due to salt present naturally in foods, and table salt added at home during cooking and eating [10] [11] [12] [13]. The same early studies also indicated that by contrast, unlike the above countries, in most Asian countries, the salt added at home during cooking or from soy sauce are the main sources of sodium in the diet. Given the way salt is ingested in these countries, a public health campaign is needed to encourage Asian consumers to use less salt in their food preparation [14] [15]. For the reasons stated above, in European and Northern American countries, human health organizations have all enjoined the food industry to reduce salt levels in manufactured food products. For example, both the US National Academy of Sciences and the French Health Agency AFSSA recommend a maximum daily intake of sodium chloride of $6 \mathrm{~g}$, which means reducing current consumption by about $50 \%$ in countries such as the US, Ireland and France. It is to be borne in mind that pork, beef, lamb and poultry meats naturally contain 50 - $70 \mathrm{mg}$ of sodium per $100 \mathrm{~g}$ [16]. 
Excessive consumption of fat has been associated with an increased risk of obesity, cancer, high blood cholesterol and coronary diseases. Accordingly, the latest recommendations [17] advise limiting the consumption of fat so that it represents no more than $30 \%$ of calorie intake in the diet, while at the same time balancing fatty acids: saturated (less than $10 \%)$, polyunsaturated $(6 \%-10 \%$, with ideally $5 \%-8 \%$ of $\omega-6$ and $1 \%-2 \%$ of $\omega-3)$, mono-unsaturated $(10 \%-15 \%)$ and trans-unsaturated (less than $1 \%$ ).

Human dietary concerns create an absolute need to develop dried-cured pork products with lower levels of sodium, saturated fatty acids, and nitrate/nitrite. More generally, large health benefits and medical costs savings may result from efforts to lower sodium, calorie and fat consumption in the human diet. He et al. [18] reported that even a modest reduction in dietary salt intake for at least four weeks caused a significant decrease in blood pressure in both normotensive and hypertensive individuals, irrespective of $\operatorname{sex}(\mathrm{p}<0.001$ for hypertensive men and both normotensive and hypertensive women, and $\mathrm{p}<0.05$ for normotensive men) and ethnic group ( $\mathrm{p}<0.001$ for hypertensive white and black people, $\mathrm{p}<$ 0.05 for hypertensive Asian people and normotensive white people and $\mathrm{p}=0.012$ for normotensive black people). For adult persons, Aburto et al. [19] conclude that lower sodium intake is assuredly associated with lower blood pressure and a reduced risk of stroke and fatal coronary heart disease, and also has no adverse effect on blood lipids or renal function. Using a cross-sectional simulation approach, Palar and Sturm [20] calculated that reducing the average daily sodium intake in the US adult population to the recommended value of $2.3 \mathrm{~g}$ could reduce cases of hypertension by 11 million and directly save $\$ 18$ billion in health care annually; coupled to moderate reductions in dietary intakes of calories $(-100 \mathrm{kcal} / \mathrm{day})$ and saturated fat $(-5 \mathrm{~g} / \mathrm{d})$, these annual financial savings could range from $\$ 60$ billion to $\$ 120$ billion [21]. In 2011, Webster et al. [22] concluded that for most countries, one of the simplest, surest and most cost-effective ways of improving public health would be to implement an ambitious national salt reduction program. Through examples covering dry-cured ham (which represented a production of 46,737 tons in 2015 in France) and dry-fermented sausage (108,825 tons in 2015 in France), this paper reviews the main technological advances made in recent years that have favored the production of dried-cured pork products with improved nutritional value.

\section{Reduction/Substitution of Sodium Chloride in Dry Pork Products}

Although excessive sodium consumption is harmful to human health, it is also true that sodium remains a major ingredient in the production of dried-cured pork products owing to its many technological functions [23] [24]. Sodium chloride is first of all a preservative: it protects a broad variety of food systems from microbiological spoilage and/or undesirable or pathogenic microorganisms, such as Clostridium botulinum and Listeria monocytogenes. Other sodium salts (e.g. sodium lactate and sodium diacetate) are also widely used in conjunction 
with sodium chloride to prevent the growth of some microorganisms in many foods. Hence any reduction in the amount of salt added to a food product may generate a real microbiological hazard, potentially shortening product shelf-life and endangering human health. Taormina [25] reviewed the antimicrobial properties of sodium chloride in foods, and addressed the impact of reducing and replacing salt and sodium on microbiological food safety and quality. Secondly, salt helps to give dried-cured pork products their characteristic flavor. Thirdly, it plays a preponderant role in the final texture of the products, for example, by its action on solubilizing the meat myofibrillar proteins. In dry-cured ham, the salt controls the enzymatic activity inside muscles by inhibiting certain proteases, such as cathepsins and aminopeptidases, thus governing the time course of proteolysis [26]. The production of dried-cured pork products with low sodium chloride content is thus far from straightforward, given the major role played by salt, as such products will not only be less salty, but will also lose some of the typical flavor of dried-cured meat [27]. The likely adverse effects of reducing sodium chloride content in dried-cured pork products include poor texture due to intense proteolysis, and poor cohesiveness, which becomes a problem when the meats are sliced, together with a reduction in the flavor and aroma typical of these products [28].

Several strategies can be used to reduce the sodium content of dried-cured pork products: direct reduction of salt level over time, partial substitution of salt by other metal salts, and the use of flavor enhancers [29].

\subsection{Direct Reduction of Sodium Chloride in Dry Pork Products}

The simplest way is to reduce, directly and gradually-or "by stealth" as described in [29] - the quantity of sodium added when the products are being manufactured [6]. This has been done by many producers over the last decades. In 1982, it was claimed that a maximum reduction of $25 \%$ in sodium content could be achieved in most processed meat products with no detrimental effects on their flavor, texture or shelf-life [30]. However, there are few studies in the literature in which the quantity of added sodium chloride has been simply reduced. We may cite Benedini et al. [28], who found that in Parma hams a simple reduction of $5.5 \%$ to $4 \%$ in salt content (total mass) resulted in notable changes in texture, aroma and taste. Even so, they report that the production of Parma hams with conserved organoleptic properties and a salt content reduced by $25 \%$ is possible, provided the ripening time is extended and the proteolysis is controlled. In another study on Corsican hams aged 18 months a reduced salting time resulted in a decrease in salt content, of $7.3 \%-4.7 \%$, but also caused rancid and buttery odors linked to the oxidation of lipids, which damaged the final acceptability of this type of product by the consumer [31]. Andrés et al. [32] and Costa-Corredor et al. [5] found a loss of salt taste and aroma, and a softer texture, detrimental to overall quality in Iberian hams and restructured Spanish hams that had undergone a 50\% reduction in salt content during manufacture. The same degree of salt reduction applied to smoked dried Portuguese sausages 
resulted systematically in significantly higher values of $a_{w}$ and $\mathrm{pH}(\mathrm{p}<0.05)$, variations in proteolysis, and ultimately in different aromatic profiles [33]. These studies show tendentially that it is very difficult to reduce sodium content by more than $25 \%$, by simply lowering the quantity of sodium chloride added to the pork products during their manufacture, without adversely affecting texture and/or aroma. In addition, for dried-fermented products, sodium chloride content cannot be simply reduced, because a low $a_{w}$ value still has to be reached to ensure the microbiological stability of the products [27].

\subsection{Partial Substitution of Sodium Chloride by Other Salts in Dry Pork Products}

Another very widely applied strategy consists in replacing some of the sodium chloride $(\mathrm{NaCl})$ by substitute salts, in particular by potassium chloride $(\mathrm{KCl})$, calcium chloride $\left(\mathrm{CaCl}_{2}\right)$, magnesium chloride $\left(\mathrm{MgCl}_{2}\right)$, potassium lactate $\left(\mathrm{C}_{3} \mathrm{H}_{5} \mathrm{KO}_{3}\right)$ or calcium ascorbate $\left(\mathrm{C}_{12} \mathrm{H}_{14} \mathrm{CaO}_{12}\right)$, which allows the overall sodium content to be lowered, while controlling $a_{w}$ inside the products. The substitute salt most often used is potassium chloride, because of its similar behavior in terms of protein solubilization and inhibition of protease activity [34]. However, at high concentrations, potassium chloride generates a strong bitter, metallic taste in products. For example, Gou et al. [35] highlighted unwanted bitterness in dry-fermented sausages, when a degree of substitution of sodium chloride by potassium chloride reached $30 \%$. However, other authors found that this defect remained acceptable up to a substitution rate of $40 \%-50 \%$, in particular in small-diameter fermented sausages [36]. Gou et al. [35] also found aroma and taste defects at rates of substitution by potassium lactate and glycine equal to $40 \%$, together with problems of texture (i.e. lower cohesiveness) for rates of substitution by potassium lactate and glycine of $30 \%$ and $40 \%$, respectively. Gelabert et al. [37] obtained much the same results, with the appearance of flavor and texture defects, from a rate of sodium chloride substitution by $\mathrm{KCl}$ of $40 \%$, by potassium lactate of $30 \%$, and by glycine of $20 \%$. These authors also found that replacing $40 \%-70 \%$ of $\mathrm{NaCl}$ by mixtures of $\mathrm{KCl}$ and potassium lactate, and of potassium lactate and glycine, was counterproductive given the severity of the flavor and texture defects observed. Gimeno et al. [38] [39] also found lower scores for texture and color intensity, and therefore a lower sensorial acceptability, when using mixtures of potassium, magnesium and calcium chlorides as partial replacers of $\mathrm{NaCl}$ during dry-fermented sausage manufacture. By contrast, Ibañez et al. [40] [41] found no significant differences between control sausages manufactured with $3 \% \mathrm{NaCl}$ and others manufactured with $1.5 \% \mathrm{NaCl}$ and $1 \% \mathrm{KCl}$. For more voluminous products like dry-cured hams, Aliño et al. [42] found that the partial substitution of sodium chloride by other salts had the effect of slowing the fall in $a_{\mathrm{w}}$ inside the product; this then required extending the low-temperature post-salting rest phase by $32 \%$, after salting with $50 \% \mathrm{NaCl}$ $+50 \% \mathrm{KCl}$, and by $52 \%$, after salting with $55 \% \mathrm{NaCl}+25 \% \mathrm{KCl}+15 \% \mathrm{CaCl}_{2}+$ $5 \% \mathrm{MgCl}_{2}$, to obtain values of $a_{\mathrm{w}}$ similar to those of control hams $(100 \% \mathrm{NaCl})$, 
and ensure the microbiological stability of these products in the rest of the manufacturing process. The authors account for the difference by the fact that divalent cations $\left(\mathrm{Ca}^{2+}, \mathrm{Mg}^{2+}\right)$ remain mostly at the surface of the ham, where they interact with proteins, slowing their diffusion toward the interior of the muscle. These results and observations are in line with those obtained previously by Blesa et al. [43]. Using the same salt mixtures as [42], Armenteros et al. [44] highlighted defects in the sensory attributes of hams containing $\mathrm{CaCl}_{2}$ and $\mathrm{MgCl}_{2}$, while hams manufactured with $50 \% \mathrm{KCl}$ scored better, except for their taste, which presented an excessive bitterness probably due to the added $\mathrm{KCl}$. These authors showed that the defects due to a $50 \% \mathrm{NaCl}$ reduction in restructured dry-cured hams could be counterbalanced by adding $\mathrm{K}$ lactate, and by performing the ham drying step at $15^{\circ} \mathrm{C}$, up to a final product weight loss of $45 \%$ [44]. For the same type of hams, Fulladosa et al. [45] observed no negative impact of adding $\mathrm{K}$ lactate on the main ham sensory attributes, i.e. color, flavor and texture.

\subsection{Enhancement of the Salty Taste Perception of Low-Salt Dry Pork Products}

The main defects generated by using substitute salts can be corrected by adding taste enhancers or masking agents, many types of which are commercially available [16]. For example, dry-fermented sausages were manufactured in which $50 \%$ of the sodium chloride was replaced by potassium chloride, and to which were optionally added lysine, and taste enhancers disodium guanylate and disodium inosinate, at $600 \mathrm{mg} / \mathrm{kg}$ [46]. The substitution of $\mathrm{NaCl}$ by $\mathrm{KCl}$ did not significantly modify either fermentation or the drying process, but defects of aroma, taste and texture, impairing overall product quality, were detected by a panel of consumers. All these defects were subsequently corrected by combined addition of lysine and the two taste enhancers. This study shows that it is possible to manufacture dry-fermented sausages that are sensorially quite acceptable provided taste enhancers are added, and in which the sodium content is reduced by $50 \%$ [46]. It must be underlined that in none of the studies presented so far did any health or safety problem arise due to the growth of harmful micro-organisms.

Several very recent studies have also shown the high potential of adding yeast extracts to enhance the aroma of low-salt, low-fat dry-fermented sausages. Campagnol et al. [47] demonstrated that supplementation with a $2 \%$ concentration of yeast extract in 50\%-sodium-reduced dry-fermented sausages increased the production of volatile compounds, thus helping to suppress the sensory defects caused by the $\mathrm{KCl}$ addition, and yielding dry-fermented sausages that presented very acceptable sensory qualities. More recently, Corral et al. [48] [49] and Flores et al. [50] confirmed that the appropriate selection and use of yeast extracts presenting aroma potential, such as Debaromyces hansenii, could offer a good strategy to enhance the sensory characteristics of reformulated dry-fermented sausages, in particular their aroma and taste qualities, but not their texture. 
However, the beneficial effect due to the yeast inoculation is far from clear when both sodium and fat reductions are combined during the dry sausage manufacture [49]. Yeast strains can also be inoculated and used as masking agents to improve the physical, chemical and sensory properties of dry-fermented sausages manufactured with entire male fat. Very recently, Corral et al. [51] showed that the inoculation of a Debaromyces hansenii strain regulated water release during ripening owing to the surface yeast growth, and lowered hardness and chewiness in dry sausages containing entire male back fat, thus conferring textural properties similar to the control products containing gilt back fat.

One further way to modulate salty taste perception is to modify the physical structure (i.e. crystal size and shape) of the sodium chloride [16] [23]. Reducing the size of undissolved salt crystals may produce a much faster dissolution in the consumer's mouth, and so a prompter and more intense perception of the salty taste of the product, even if the total quantity of salt is lower [52]. In their review, Weiss et al. [23] indicate that a change in the physical state of the salt from crystalline to amorphous allows a 20 - to 100 -fold reduction in sodium chloride particle size. However, the perception of a salty taste and the salt-brain relation underlying it require further research to elucidate the mechanisms in play and find ways to "mislead" the brain [53]. For example, Lawrence et al. [54] have shown that certain carefully chosen odors (bacon and anchovy, among others) can compensate for defects arising from a reduction of sodium chloride content in solid foodstuffs. This strategy, called odor-induced saltiness enhancement (OISE), was also successfully tested for enhancing saltiness in low-salt content cheese models [55]. Recently, the approach using congruent aromas was even extended to compensate for loss of both saltiness and of fat perception in low-fat and low-salt cheese-like solid foods, thus highlighting a complex interaction between the effect of the composition and structure of the products and the odorinduced salt and fat perception enhancement [56].

\section{Reduction/Substitution of Animal Fat in Dry-Fermented Sausage}

As a result of drying, pork products like dry-fermented sausage or salami can ultimately contain $30 \%-50 \%$ animal fat. This fat proportion is a major determinant of the final sensory characteristics (flavor, texture, juiciness and appearance) of this type of product. It also manifestly deters persons with cardiovascular diseases or who are overweight from consuming these products [23]. Besides the quantity of fat consumed, its qualitative composition impacts strongly on human health. For example, ensuring cardiovascular health demands a very low consumption of trans fatty acids (less than 1\%) and a sufficient supply of polyunsaturated fatty acids (PUFAs 6\% - 10\%) in the daily energy intake, with the further constraint that these PUFAs should be well balanced between $\omega-6$ (5\% $8 \%)$ and $\omega-3(1 \%-2 \%)$, with a ratio of $1-4$ [17]. However, today's Western diets are poor in $\omega-3$ and very rich in $\omega$-6 PUFAs, with a $\omega-6 / \omega-3$ ratio between 15 and 20, very far from what is advocated [57]. Reducing the animal fat content of 
dry-fermented sausages may require reformulation of the product. A product composed of lean meat, vegetable instead of animal fat, and other fat substitutes, associated with appropriate manufacturing conditions, can help modify the lipid profile and fat concentration [23].

\subsection{Direct Reduction of Animal Fat in Dry-Fermented Sausage}

Simply reducing the animal fat content leads predictably to a loss of aroma, often not readily accepted by the consumer. From experiments on dried sausages in which fat content ranged between $10 \%$ and $30 \%$, Olivares et al. [58] found that the reduction in fat slowed lipolysis, lipid oxidation, and the ensuing formation of volatile compounds. Their results also showed that consumer acceptance was closely correlated with high fat levels and long ripening times. In a preceding study, Olivares et al. [59] had determined that the limit between acceptability and rejection by consumers of fat-reduced dry-fermented sausages corresponded to an initial fat content of $16 \%$, which leaves room for a reduction of about $50 \%$ relative to the trade standard. Lorenzo and Franco [60] have shown that high fat levels confer a bright color and a more flexible texture, and favor the production of free fatty acids, in the case of sausages manufactured from a mixture of horse meat and pork fat (5\% - 20\%). In addition, several very recent studies report on work designed to substitute some of the animal fat by cellulose gels derived from maize fiber, or konjac glucomannane, a polysaccharide extracted from a plant native to South-East Asia. Campagnol et al. [61] have shown that it is possible to replace $50 \%$ of pork fat by a cellulose gel without adversely affecting the quality of the sausages, and manufacture products with fat and cholesterol levels reduced by $45 \%$ and $15 \%$, respectively. Despite some differences in texture, dryfermented sausages, in which $50 \%$ and $80 \%$ of pork fat were replaced by konjac gel, were judged acceptable by a panel of tasters [62]. Very recently, Alejandre et al. [63] successfully investigated a high $\omega$-3 content carrageenan gelled emulsion as an animal fat replacer in order to improve the fatty acid composition of dry-fermented sausages. They showed that the level of animal fat replacement could reach $32.8 \%$ without causing any relevant defects in terms of instrumental color properties, taste and juiciness of end products.

\subsection{Incorporation of Dietary Fiber in Dry-Fermented Sausage}

The consumption of dietary fiber is known to be beneficial to human health. Accordingly, many recent studies have set out to quantify the effect of adding fiber, often of plant origin, as a functional ingredient, on the sensory and health safety properties of dry-fermented sausages with reduced animal fat content. García et al. [64] studied the effect of adding fiber from fruits (peach, apple and orange) and cereals (wheat and oats), at concentrations of $1.5 \%$ and $3 \%$, on the sensory properties of dry-fermented sausages initially containing only $6 \%$ and $10 \%$ pork fat. The best sensory results were obtained for sausages manufactured with $10 \%$ pork fat and $1.5 \%$ fiber from oranges. Adding more fiber yields products that are too hard, and that present problems of cohesiveness. These results 
confirm those of Fernández-López et al. [65], who showed that it was possible to add $1 \%$ orange fiber during the manufacture of sausages without harming flavor. This addition also seems to protect against the formation of rancidity, and leads to a decrease in residual nitrite level. The same type of result was obtained in dry-cured sausages, when incorporating up to $50 \mathrm{~g} \cdot \mathrm{kg}^{-1}$ dehydrated raw lemon albedo or $75 \mathrm{~g} \cdot \mathrm{kg}^{-1}$ dehydrated cooked lemon albedo [66]. Mendoza et al. [67] also tested the incorporation of powdered inulin, and demonstrated the feasibility of manufacturing dry-fermented sausages with $40 \%$ - 50\% less pork fat, and $30 \%$ fewer calories, but enriched with 10\% dietary fiber. Adding fiber from carrots is another possibility, provided its concentration does not exceed $3 \%$ to avoid products of poor quality with problems of fermentation, and subsequently of texture [68]. By developing a multi-layer feed forward artificial neural network, Eim et al. [69] placed at exactly $4.9 \%$ the highest content of carrot dietary fiber that could be added to dry-fermented sobrassada-type sausages, and that yielded end products with quality characteristics similar to the reference products not containing fiber. Recently, Sanchéz-Zapata et al. [70] investigated the effect of adding tiger nut fiber (from $1 \%$ to $2 \%$ ) alone or combined with walnut oil (2.5\% - 5\%) on some physical, chemical, microbial and sensory parameters in dry-cured sausages, thus demonstrating the utility of incorporating tiger nut fiber, which is rich in antioxidant compounds, to control the increase in lipid oxidation that occurs when walnut oil alone is added. Lastly, Salazar et al. [71] have shown that adding short-chain fructo-oligosaccharides, recognized as prebiotics, at initial concentrations of $2 \%, 4 \%$ and $6 \%$, does not modify the sensory qualities of the products, while at the same time fat content could be reduced by up to $58 \%$, and up to $8.7 \%$ of fiber introduced in the final product.

\subsection{Incorporation of Oil in Dry-Fermented Sausage}

Incorporating oils from plants, fish or microalgae is also a promising technological path to improving the lipid profile of sausages by increasing the levels of unsaturated versus saturated fatty acids. Among the oils tested, we may cite linseed oil at $3.3 \%$ [72], olive oil at up to $20 \%$ [73] [74], soybean oil at $20 \%$ [75], deodorized fish oil at 30\% [76] [77] and oil from micro-algae at 15\% [78]. Most of these oils were incorporated as emulsions, or even microencapsulated, in order to facilitate mixing with the chopped pork meat. Recently, Lorenzo et al. [79] manufactured Spanish salchichón presenting a better lipid profile by partially substituting up to $75 \%$ of the pork backfat by microencapsulated fish oil in a konjac glucomannane matrix. They concluded that this reformulation procedure was technologically feasible, but most of the sensorial properties and also lipid oxidation were significantly affected. Jiménez-Colmenero et al. [80] investigated the use of a healthy oil combination (olive, linseed and fish oils) previously stabilized in a konjac matrix as a pork fat replacer with the objective of enhancing the lipid composition of dry-fermented sausages. Although this reformulation procedure predictably improved the $\omega-6 / \omega-3$ ratio in the end products, at the same time it degraded all the sensorial parameters compared with controls [80]. 
However, as a general rule, when the oil concentrations and substitution rates exceed a certain limit, unacceptable defects ensue during dry sausage manufacture, resulting, in particular, in loss of oil. At a moderate level of incorporation, which varies according to the oil used, the dry-fermented sausages obtained present a highly significant increase in their unsaturated fatty acid fractions, and a marked reduction in cholesterol level, and so an appreciable improvement in their nutritional qualities [81]. However, care must be taken not to let adding oils increase lipid oxidation. With this in mind, antioxidants are often associated with oil incorporation. The current trend is to add naturally-occurring antioxidants extracted from plants, although they seem less efficient than synthetic antioxidants such as butylhydroxyanisol (BHA) and butylhydroxytoluene (BHT), which are suspected of favoring the formation of certain cancers. García-Iñiguez de Ciriano et al. [82] successfully demonstrated the ability of extracts from borage leaves at a concentration of 340 ppm per $\mathrm{kg}$ to retard oxidation in Pamplona chorizos enriched with $\omega$-3 polyunsaturated fatty acids, by substitution of $25 \%$ of the quantity of pork fat by a linseed oil emulsion. In Turkish dried sausages, Bozkurt [83] showed that the efficiency of naturally-occurring antioxidants like sesame oil or the oil of Thymbra spicata was as high as that of BHT, as regards oxidation, and appreciably greater as regards the formation of biogenic amines such as putrescine and histamine; the three ingredients tested were all added at a concentration of 300 ppm per kg. Recently, Ba et al. [84] studied the antioxidant and anti-bacterial effects of extracts from shiitake by-products in dry-fermented sausages during their storage for up to 30 days, at $15^{\circ} \mathrm{C}$. Analyzing their results clearly shows that this extract, when added at a level of $0.6 \%$, strongly limited the increase in lipid oxidation during the product storage, as well as the growth of pathogens such as Staphylococcus aureus, Listeria monocytogenes and Escherichia coli O157 [84]. Lastly, the incorporation of carotene by adding tomato skin powder (up to $1.2 \%$ ) to dry-fermented sausages was successful, and may prove an effective way to limit lipid oxidation, while at the same time making gainful use of an industrial by-product [85]. We note that the use by the food industry of antioxidants derived from industrial natural by-products, e.g. tomato or shiitake extracts, is to be encouraged as part of a sustainable development approach.

\section{Reduction of Nitrate/Nitrite in Dried-Cured Pork Products}

The use of nitrate in pork products goes back to ancient times. The first explanations for its mode of action were given at the end of the $19^{\text {th }}$ century. In 1901, Haldane (cited by Dabin and Jussiaux [86]) was the first to account for the effect of nitrite on meat color, which occurs after the binding of nitric oxide (NO) by myoglobin. The valence of iron $\left(\mathrm{Fe}^{2+}\right.$ or $\left.\mathrm{Fe}^{3+}\right)$ contained in myoglobin determines its color. Oxidation of the iron and simultaneous binding of nitric oxide from the reduction of nitrite causes nitrosometmyoglobin to form, which in turn is reduced to nitrosomyoglobin, the red color of which is stable at low $a_{w}$ values. Unlike nitrate, nitrite also has a bacteriostatic or even bactericidal action, in par- 
ticular on Clostridium and enterobacteria such as Salmonella and coliforms. Lastly, both nitrate and nitrite give meats the taste and odor characteristic of salted-dried products. Nitrite limits lipid oxidation and retards the development of rancidity, and so forestalls the appearance of undesirable flavors during storage [23]. In the manufacture of dried-cured pork products with long ripening times, nitrite is the active substance in salting-drying, nitrate acting as a reserve for nitrite formed by microbial action throughout the process [87].

Nitrite is toxic when consumed in large doses. It converts hemoglobin into methemoglobin, which prevents all oxygen transport to the tissues in the body, causing cyanosis if more than $20 \%$ of the hemoglobin is converted. Nitrite is some 10 times more toxic than nitrate: in humans, the lethal oral doses are in the range 80 - $800 \mathrm{mg}$ of nitrate/kg body weight and 33 - $250 \mathrm{mg}$ of nitrite/kg body weight [88]. In addition to this direct toxicity, nitrite can also indirectly combine with amines derived from the breakdown of meat proteins, for example during proteolysis. Under certain conditions (temperature above $130^{\circ} \mathrm{C}$, acidic medium), nitrosamines are formed, some of which are recognized mutagenic substances that can induce carcinogenic effects [89] [90]. The use of nitrate/nitrite is thus regulated in many countries, where nitrite may be used only as a mixture with sodium chloride containing less than 1\% nitrite ("curing salt"). Since 2006 in France no more than $300 \mathrm{mg} / \mathrm{kg}$ of nitrite plus nitrate can be added to unheated pork products to be dried and ripened. However, it is generally accepted that in the human diet, most nitrite comes from dried-cured meat products, but most nitrate $(70 \%-90 \%)$ is supplied in vegetables and drinking water. Hsu et al. [91] recorded nitrate concentrations of up to $5000 \mathrm{mg} / \mathrm{kg}$ in spinach; in meat products, the highest value was found in salamis, with $140 \mathrm{mg} / \mathrm{kg}$. For nitrite, these same authors found levels below $87 \mathrm{mg} / \mathrm{kg}$ and $23 \mathrm{mg} / \mathrm{kg}$ in meat products and vegetables, respectively. Alongside exogenous intake due to direct ingestion of nitrite, nitrate is converted into nitrite in the human mouth and stomach [92], forming an endogenous nitrite source that may be responsible for most of the nitrite present in the stomach. Because of its acidity, and the presence of large amounts of nitrite, the stomach makes a very good reactor for the synthesis of nitrosamines. Exposure to endogenously-formed nitrosamines has been associated with increased risk of cancers of the stomach, esophagus and bladder [93]. Moreover, Joosens et al. [94] highlighted a synergistic effect of dietary nitrate and high sodium intakes as risk factors for stomach cancer mortality. Accordingly, although residual levels of nitrate and nitrite present in dried-cured pork products are not hazardous, except in the case of a manufacturing accident, there is strong pressure of public opinion to minimize or even ban the use of nitrate in foods, including dried-cured products.

Like for sodium chloride, the reduction or even the complete banning of nitrate/nitrite is far from straightforward, because of the many reactions both positive and negative caused by contact between nitrite and the different components of the meat matrix, and can raise problems. This complexity prompted Jiménez-Colmenero et al. [95] to assert that it would be impossible to find a sin- 
gle substance able to perform all the functions of nitrite. Only combinations of several substances could be expected to produce the positive effects of nitrite on color and aroma, and exert its antimicrobial and antioxidant activities. Pichner et al. [96] confirmed that simply removing nitrate and nitrite from salamis, without sufficient technological knowledge to correct the process, led to products of very poor quality, both sensory (no typical coloration at the core of the products) and microbiological (survival of Gram-negative bacteria). In their study, Hospital et al. [97] also confirmed the essential barrier role played by nitrate/nitrite, in the same way as $\mathrm{pH}$ and $a_{\mathrm{w}}$, against the growth of Salmonella typhimurium in dry-fermented sausages. Not adding nitrate/nitrite to the meat batches led to an increase of $2-2.5 \mathrm{log} \mathrm{cfu} / \mathrm{g}$ in the Salmonella population in the end products. However, these authors observed experimentally that reducing the amount of nitrate and nitrite by $50 \%$ led to the same inhibitory effect against Salmonella typhimurium as the maximum amount allowed by the EU (300 mg) [97].

One other way to reduce direct addition of nitrite and nitrate is to incorporate nitrate-rich powdered vegetables (celery, beetroot, and leek, among others). This requires adding microbial flora to ensure the reduction of nitrate to nitrite. Tsoukalas et al. [98] have shown that adding $0.84 \%$ leek powder, supplying 75 $\mathrm{mg} / \mathrm{kg}$ of nitrate, associated with $75 \mathrm{ppm}$ of nitrite, in no way modified the fermentation and drying steps, and allowed the same organoleptic and sensory qualities to be conserved during the manufacture of dry-fermented sausages. This addition allowed a $50 \%$ reduction in the use of nitrate, and eliminated the use of "chemical" nitrate. From a trial conducted with a stepwise assay of nitrate, Schlüchter et al. [99] showed that during the manufacture of salamis, saltpeter, a source of nitrate, could be partly replaced by powdered vegetables, with no microbiological hazard. However, high levels of vegetable powder gave the salami lower peelability and a firmer consistency. In addition to directly reducing the quantity of nitrate and/or nitrite added during manufacture, one possible approach would be to intervene directly in the chain of reactions leading to the formation of nitrosamines, using antioxidants such as vitamin $\mathrm{C}$, polyphenols, ascorbate, or erythorbate, which would inhibit their formation [95] [100].

The issue of nitrate/nitrite in dried pork products is compounded by the seemingly paradoxical case of Parma ham, to which sodium chloride alone is added during manufacturing, without any microbiological problem or color defect occurring. Even though no nitrate or nitrite is added to the sodium chloride, the color of Parma ham is "mysteriously" bright red, and highly stable. Wakamatsu et al. [101] suggested that the typical red color of Parma ham came from a substance, zinc protoporphyrin IX (ZPP), in which the iron atom of heme has been replaced by an atom of zinc, a metal abundant in pork. The enzyme zinc-chelatase was thought to be involved in this reaction, by catalyzing the substitution of iron by zinc; the activation of this enzyme may be greater in the presence of salt [102]. A few years later, Wakamatsu et al. [103] found there was in fact no iron-zinc substitution in heme, but instead the insertion of an atom of zinc di- 
rectly in protoporphyrin. More recently, Wakamatsu et al. [104] went on to show that adding nitrite to dried-cured pork products, through the formation of nitric oxide (NO), inhibited the formation of protoporphyrin IX, the precursor of the protoporphyrin-zinc IX complex, responsible for the typical color of Parma ham. This mechanism may explain why the ZPP complex occurs in small quantities in dried-cured pork products in which nitrite is incorporated, in contrast to Parma ham [105]. In addition to sodium chloride, it would seem that adding ascorbate enhances the formation of ZPP. This mechanism thus offers an interesting avenue for obtaining satisfactorily colored dried-cured pork products without adding nitrite.

The use of nitrate/nitrite in the manufacture of dried-cured pork products draws criticism and remains controversial. Should these substances be banned, given the direct and indirect toxicity of nitrite? Or should they continue to be authorized in strictly limited quantities, in view of their many positive effects on the sensory and health safety qualities of dried-cured pork products? These questions remain open, especially since several recently published studies have pointed to the positive human health benefits of a diet rich in nitrate/nitrite, through the formation of nitric oxide, deficiency of which has been demonstrated medically to cause several health disorders [106] [107] [108] [109]. Lundberg et al. [107] go further, advocating a fresh view of nitrate/nitrite, looking at it not as a threat to human health, but rather as an essential nutrient in our diet. Partasarathy and Bryan [109] conclude by reminding us of the dual meaning of the term "cure", suggesting that the ancient "curing" agent nitrate/nitrite might soon be seen more as a health "cure". What is certain is that further studies are warranted to elucidate all the mechanisms involved in the nitrite chemistry and its interactions with the components of the meat matrix, both during the manufacture of the cured red meat products and during the digestion in the human stomach and gut of these meat products, which are commonly consumed, in a diet, in combination with water, fruits and vegetables.

\section{Toward Dried-Cured Pork Products with Higher Nutritional Value}

Reducing the sodium content of dry-cured pork products, and associating a reduction in their animal fat content, manifestly helps improve the nutritional value of these food products. Although the scope for action seems more limited than for cooked pork products like frankfurters, several studies have been conducted in recent years to further improve the nutritional profile of dry-fermented pork products (sausage, salami, etc.), by modifying their lipid profile or by incorporating dietary fiber or naturally-occurring antioxidants. Dry-fermented sausages to which probiotics have been added have even been successfully produced [110] [111]. Several recent reviews deal with this subject [23] [81] [95] [100] [112] [113] [114] [115] [116]. However, whenever a new substance is incorporated, or sodium or fat contents are changed, it is essential to evaluate the consequences of these changes on the organoleptic, health safety and sensory 
qualities of the "new" products. Furthermore, all the qualities of these new products are most often expected to resemble those of the equivalent unmodified product, whereas some differences are inevitable, in particular in the typical flavor. This may therefore not be the best approach to successfully market pork products with improved nutritional qualities.

Until the last two years, there have been very few studies on combining sodium and animal fat reductions in dried fermented pork products, doubtlessly because these two reductions jointly cause a very marked loss of the aroma and typical taste expected of such products. These studies include the work of Beriain et al. [117] designed to quantify the effect of replacing half the pork fat by an emulsion of water, olive oil and alginate, incorporating inulin, and substituting $58 \%$ of the sodium chloride by $20 \%$ potassium chloride and $38 \%$ calcium chloride, on the qualities of Pamplona chorizo. Trials showed that the incorporation of olive oil in an emulsion, associated with a $58 \%$ reduction of sodium chloride, had no negative effect on the technology of the manufacturing process, no abnormal difference in the time course of $\mathrm{pH}$ or microbiological populations being detected at any time during manufacture. Chorizos containing alginate were shinier and harder than traditional ones, except for those also containing 6\% inulin. In conclusion, this work showed that by combining the incorporation of an emulsion based on alginate and olive oil with added inulin, it was possible to manufacture Pamplona chorizos with less salt and less fat, but with more unsaturated fatty acids, thereby offering products with a better nutritional profile than those manufactured traditionally [117]. Recently, Safa et al. [118] investigated the effect of direct combined salt and animal fat reductions on the time course of several physical, chemical and biochemical parameters during the manufacture of dry-fermented sausages. Briefly, their results showed that direct combined salt and fat reductions increased the acidification, product weight losses and final $a_{w}$, amplified the proteolysis and lowered the lipolysis and protein and lipid oxidations, thus probably altering the end product sensory attributes. In another very recent study [119], the same authors quantified the effects of combined partial substitutions of $\mathrm{NaCl}$ by $\mathrm{KCl}$ and of pork backfat by sunflower oil on key physical, chemical and biochemical parameters, on end product instrumental color and texture, and finally on the consumer acceptability of the new dry-fermented sausages manufactured. They demonstrated that sodium and SFA contents can be drastically reduced in dry-fermented sausages (up to $30 \%$ for sodium and $60 \%$ for SFA, respectively) without too marked defects in final textural properties, color or consumer acceptability [119]. The same type of study was performed for small-caliber non-acid fermented sausages by MoraGallego et al. [120], who found that a combined reduction of $\mathrm{NaCl}$ and fat contents, from $2.5 \%$ to $1.5 \%$ and from $33.2 \%$ to $15.1 \%$, respectively, increased consumer acceptability, and also $a_{\mathrm{w}}$. This increase in $a_{\mathrm{w}}$ was then partially offset by adding $0.64 \% \mathrm{KCl}$ and $1.5 \%$ sunflower oil, which finally constituted the formulation preferred by consumers.

Dry-cured ham, which takes from 6 to sometimes more than 24 months to 
manufacture, is a whole product treated by surface salting. Hence the only scope for action is a reduction in the sodium content, offset by an increase in potassium or calcium content. However, care must be taken when modifying the process, given that some studies [42] [43] have shown that simply replacing about $50 \%$ of the sodium chloride by other salts increased the post-salting rest phase by $30 \%-50 \%$, depending on the salts used, owing to the increase in the value of $a_{w}$. When studying the reduction of sodium content in dry-cured hams, $\mathrm{X}$-ray tomography is a useful tool for the continuous non-destructive monitoring of salt and water transfers throughout the manufacturing process. Recently, Fulladosa et al. [121] and Santos-Garcés et al. [122] [123] showed that water and salt contents, together with $a_{w}$, could be estimated at different stages in the manufacture of dry-cured hams, from images obtained by X-ray tomography. Ultimately, by favoring the formation of the zinc-protoporphyrin complex responsible for the stable red color typical of Parma ham, the incorporation of nitrate/nitrite could also be discontinued in other types of dry-cured ham.

Incorporating salts containing potassium as a sodium chloride substitute in dried-cured pork products may offer one way to increase potassium consumption in the human diet, which is generally very deficient in the populations of developed countries. Very recently, Aburto et al. [124] obtained statistical results suggesting that increased potassium intake is potentially beneficial to persons with no kidney disorder for the prevention and control of elevated blood pressure and stroke. We note that according to Castro and Raij [125], human well-being in terms of blood pressure and cardiovascular health may be related to the sodium-to-potassium diet intake ratio rather than to each nutrient rate taken individually. These authors thus advocate implementing a low sodiumhigh potassium diet as a crucial strategy for both preventing and treating human hypertension and cardiovascular disease. Moreover, it would seem that potassium intake at recommended level constitutes an optimal strategy to protect the skeleton against osteoporosis, because it prevents sodium chloride-induced calciuria [7].

Processed meat products may also become a very useful way to supply calcium in the human diet, as they are consumed by all population age groups. Accordingly, Gimeno et al. [126] tried adding calcium ascorbate (26\% - 50\% of recommended daily intake) to dry-fermented sausages, with the aim of reducing the sodium chloride content of these products (from 15\% to 45\%). In summary, their work showed that the use of calcium ascorbate was an efficient way to reduce sodium content in dry-fermented sausages, while at the same time enriching them in calcium ascorbate. However, no sensory testing was done on these products. Adding calcium to meat products thus seems to be a nutritionally important avenue, especially as several recent studies in rats show tendentially that intake of calcium (here as calcium carbonate) at the same time as red meat is beneficial in reducing colonic cancer risk [127] [128]. However, as calcium traps heme iron, problems may arise, given that iron deficiency is one of the most common nutritional disorders in certain population groups, in particular preg- 
nant women. To avoid excessive trapping of heme iron, while at the same time reducing the risks of carcinogenesis linked to the consumption of red meat and dried-cured pork products, another approach would be to limit lipid peroxidation and the formation of nitrosamines by incorporating antioxidants in foods [127].

Besides sodium, SFAs and nitrite, dry-cured pork products are also criticized for their high cholesterol levels. Nutritional recommendations prescribe a daily intake of cholesterol in food no higher than $300 \mathrm{mg}$. Meat generally contains 77 $95 \mathrm{mg}$ of cholesterol per $100 \mathrm{~g}$, except for some offal, which contains more than $300 \mathrm{mg}$ [129]. We emphasize that replacing some of the animal fat by lean meat does not necessarily mean that cholesterol levels are lowered, as the cholesterol and fat contents of meat are not correlated [95]. An effective way to reduce cholesterol level in dried-cured pork products is to replace some of the lean meat and the animal fat by proteins or fat of plant origin, as plant tissues contain little cholesterol. Another way to address the issue of cholesterol in dried-cured pork consumption would be to increase their conjugated linoleic acid content [23].

\section{Conclusion}

Reducing the levels of sodium and saturated fatty acids in dried-cured pork products, and no longer adding nitrate/nitrite, thereby enhancing the nutritional value of these products, are central to current issues facing meat professionals, i.e. manufacturers, technologists, researchers, applied scientists, etc. These actions seem essential to restore the public image of processed pork products, especially now that many consumers are ready to accept dried-cured products that are salt-reduced, fat-reduced and nitrite-free [130]. The consumption of driedcured pork products is nutritionally beneficial in terms of ingested proteins, because of their concentration after drying, and given their essential amino acid profile, which is well-balanced and close to human requirements. Knowing what we eat, and keeping to a varied, balanced and moderate diet, are essential factors in healthy human nutrition. Achieving a balanced diet is the consumer's responsibility, but the food industry, and in particular the meat industry, must be able to provide the consumers with a broad range of products that meet their demands. This will only be possible if a multidisciplinary approach is set up associating scientists (food scientists, process engineers, modeling experts, microbiologists, biochemists, toxicologists, nutritionists, etc.), pork professionals and technologists, leading, for example, to the development of computer-aided decision-making tools, making it possible to virtually design either the dry-cured meat products or the manufacturing processes associated with these foodstuffs. The "numerical dry-cured ham" model recently built [131] offers a good example of the type of numerical tools we will have to develop in the near future to help professionals manufacture new, healthier dry-cured meat products.

\section{Acknowledgements}

This review was written as part of the Na-integrated program (ANR-09-ALIA013-01) financed by the French National Research Agency, as part of the Euro- 
pean Union Seventh Framework Programme (FP7/2007-2013) under grant agreement No. 289397 (TeRiFiQ project) and as part of the FUI-15 MEATIC program financed by BPI France, Région Bretagne and Région Pays de Loire.

\section{References}

[1] Leistner, L. (1985) Hurdle Technology Applied to Meat Products of the Shelf Stable Product and Intermediate Moisture Food Types. In: Simatos, D. and Multon, J.L., Eds., Properties of Water in Foods in relation to Quality and Stability, Martinus Nijhoff Publishers, Dordrecht, 309-329. https://doi.org/10.1007/978-94-009-5103-7_19

[2] Flores, J. (1997) Mediterranean vs Northern European Meat Products. Processing Technologies and Main Differences. Food Chemistry, 59, 505-510.

[3] Guerrero, L., Guardia, M.D., Xicola, J., Verbeke, W., Vanhonacker, F., Zakowska-Biemans, S., Sajdakowska, M., Sulmont-Rosse, C., Issanchou, S., Contel, M., Scalvedi, M.L., Granli, B.S. and Hersleth, M. (2009) Consumer-Driven Definition of Traditional Food Products and Innovation in Traditional Foods. A Qualitative Cross-Cultural Study. Appetite, 52, 345-354.

[4] Wirth, F. (1988) Technologies for Making Fat-Reduce Meat Products. What Possibilities Are There? Fleischwirtschaft, 68, 1153-1156.

[5] Costa-Corredor, A., Serra, X., Arnau, J. and Gou, P. (2009) Reduction of NaCl Content in Restructured Dry-Cured Hams: Post-Resting Temperature and Drying Level Effects on Physicochemical and Sensory Parameters. Meat Science, 83, 390 397.

[6] He, F.J. and MacGregor, G.A. (2009) A Comprehensive Review on Salt and Health and Current Experience of Worldwide Salt Reduction Programmes. Journal of $\mathrm{Hu}$ man Hypertension, 23, 363-384. https://doi.org/10.1038/jhh.2008.144

[7] Heaney, R.P. (2006) Role of Dietary Sodium in Osteoporosis. Journal of the American College of Nutrition, 25, 271S-276S. https://doi.org/10.1080/07315724.2006.10719577

[8] Nazario, C.M., Szklo, M., Diamond, E., Román-Franco, A., Climent, C., Suarez, E. and Conde, J.G. (1993) Salt and Gastric Cancer: A Case-Control Study in Puerto Rico. International Journal of Epidemiology, 22, 790-797. https://doi.org/10.1093/ije/22.5.790

[9] McMahon, E.J., Campbell, K.L., Mudge, D.W. and Bauer, J.D. (2012) Achieving Salt Restriction in Chronic Kidney Disease. International Journal of Nephrology, 2012, Article ID: 720429. https://doi.org/10.1155/2012/720429

[10] Brown, I.J., Tzoulaki, I., Candeias, V. and Elliott, P. (2009) Salt Intakes around the World: Implications for Public Health. International Journal of Epidemiology, 38, 791-813. https://doi.org/10.1093/ije/dyp139

[11] James, W.P., Ralph, A. and Sanchez-Castillo, C. (1987) The Dominance of Salt in Manufactured Food in the Sodium Intake of Affluent Societies. The Lancet, 329, 426-429. http://linkinghub.elsevier.com/retrieve/pii/S0140673687901279 https://doi.org/10.1016/s0140-6736(87)90127-9

[12] Mattes, M. and Donnelly, D. (1991) Relative Contributions of Dietary Sodium Sources. Journal of American College of Nutrition, 10, 383-393. https://doi.org/10.1080/07315724.1991.10718167

[13] Sanchez-Castillo, C.P., Warrender, S., Whitehead, T.P. and James, W.P. (1987) An Assessment of the Sources of Dietary Salt in a British Population. Clinical Science, 72, 95-102. 
[14] He, F.J. and MacGregor, G.A. (2010) Reducing Population Salt Intake Worldwide: From Evidence to Implementation. Progress in Cardiovascular Diseases, 52, 363 382. http://linkinghub.elsevier.com/retrieve/pii/S0033062009001273?showall=true https://doi.org/10.1016/j.pcad.2009.12.006

[15] He, F.J., Jenner, K.H. and MacGregor, G.A. (2010) WASH-World Action on Salt and Health. Kidney International, 78, 745-753. https://doi.org/10.1038/ki.2010.280

[16] Desmond, E. (2006) Reducing Salt: A Challenge for the Meat Industry. Meat Science, 74, 188-196.

[17] Nishida, C., Uauy, R., Kumanyika, S. and Shetty, P. (2004) The Joint WHO/FAO Expert Consultation on Diet, Nutrition and the Prevention of Chronic Diseases: Process, Product and Policy Implications. Public Health Nutrition, 7, 245-250. https://doi.org/10.1079/PHN2003592

[18] He, F.J., Li, J. and Macgregor, G.A. (2013) Effect of Longer Term Modest Salt Reduction on Blood Pressure: Cochrane Systematic Review and Meta-Analysis of Randomised Trials. British Medical Journal, 346, f1325. https://doi.org/10.1136/bmj.f1325

[19] Aburto, N.J., Ziolkovska, A., Hooper, L., Elliott, P., Cappuccio, F.P. and Meerpohl, J.J. (2013) Effect of Lower Sodium Intake on Health: Systematic Review and Meta-Analyses. British Medical Journal, 346, f1326. https://doi.org/10.1136/bmj.f1326

[20] Palar, K. and Sturm, R. (2009) Potential Societal Savings from Reduced Sodium Consumption in the U.S Adult Population. American Journal of Health Promotion, 24, 49-57.

[21] Dall, T.M., Fulgoni, V.L., Zhang, Y., Reimers, K.J., Packard, P.T. and Astwood, J.D. (2009) Potential Health Benefits and Medical Cost Savings from Calorie, Sodium and Saturated Fat Reductions in the American Diet. American Journal of Health Promotion, 23, 412-422.

[22] Webster, J.L., Dunford, E.K., Hawkes, C. and Neal, B.C. (2011) Salt Reduction Initiatives around the World. Journal of Hypertension, 29, 1043-1050.

https://doi.org/10.1097/HJH.0b013e328345ed83

[23] Weiss, J., Gibis, M., Schuh, V. and Salminen, H. (2010) Advances in Ingredient and Processing Systems for Meat and Meat Products. Meat Science, 86, 196-213.

[24] Pretorius, B. and Schönfeldt, B.C. (2016) The Contribution of Processed Pork Meat Products to Total Salt Intake in the Diet. Food Chemistry, in press.

[25] Taormina, P.J. (2010) Implications of Salt and Sodium Reduction on Microbial Food Safety. Critical Reviews in Food Science and Nutrition, 50, 209-227. https://doi.org/10.1080/10408391003626207

[26] Toldrá, F. (2006) The Role of Muscle Enzymes in Dry-Cured Meat Products with Different Drying Conditions. Trends in Food Science and Technology, 17, 164-168.

[27] Ruusunen, M. and Puolanne, E. (2005) Reducing Sodium Intake from Meat Products. Meat Science, 70, 531-541.

[28] Benedini, R., Parolari, G., Toscani, T. and Virgili, R. (2012) Sensory and Texture Properties of Italian Typical Dry-Cured Hams as related to Maturation Time and Salt Content. Meat Science, 90, 431-437.

[29] Inguglia, E.S., Zhang, Z., Tiwari, B.K., Kerry, J.P. and Burgess, C.M. (2017) Salt Reduction Strategies in Processed Meat Products-A Review. Trends in Food Science \& Technology, 59, 70-78.

[30] Olson, D.G. (1982) Salt for Processing Probably Can Be Cut by Only One Quarter. The National Provisioner, 17, 7-10.

[31] Coutron-Gambotti, C., Gandemer, G., Rousset, S., Maestrini, O. and Casabianca, F. 
(1999) Reducing Salt Content of Dry-Cured Ham: Effect on Lipid Composition and Sensory Attributes. Food Chemistry, 64, 13-19.

[32] Andres, A.I., Cava, R., Ventanas, J., Thovar, V. and Ruiz, J. (2004) Sensory Characteristics of Iberian Ham: Influence of Salt Content and Processing Conditions. Meat Science, 68, 45-51.

[33] Roseiro, L.C., Santos, C., Sol, M., Borges, M.J., Anjos, M., Goncalves, H. and Carvalho, A.S. (2008) Proteolysis in Painho de Portalegre Dry Fermented Sausage in relation to Ripening Time and Salt Content. Meat Science, 79, 784-794.

[34] Armenteros, M., Aristoy, M.C., Barat, J.M. and Toldrá, F. (2009) Biochemical Changes in Dry-Cured Loins Salted with Partial Replacements of $\mathrm{NaCl}$ by $\mathrm{KCl}$. Food Chemistry, 117, 627-633.

[35] Gou, P., Guerrero, L., Gelabert, J. and Arnau, J. (1996) Potassium Chloride, Potassium Lactate and Glycine as Sodium Chloride Substitutes in Fermented Sausages and in Dry-Cured Pork Loin. Meat Science, 42, 37-48.

[36] Guardia, M.D., Guerrero, L., Gelabert, J., Gou, P. and Arnau, J. (2008) Sensory Characterisation and Consumer Acceptability of Small Calibre Fermented Sausages with $50 \%$ Substitution of $\mathrm{NaCl}$ by Mixtures of $\mathrm{KCl}$ and Potassium Lactate. Meat Science, 80, 1225-1230.

[37] Gelabert, J., Gou, P., Guerrero, L. and Arnau, J. (2003) Effect of Sodium Chloride Replacement on Some Characteristics of Fermented Sausages. Meat Science, 65, 833-839.

[38] Gimeno, O., Astiasarán, I. and Bello, J. (1998) A Mixture of Potassium, Magnesium and Calcium Chloride as a Partial Replacement of Sodium Chloride in Dry Fermented Sausages. Journal of Agricultural and Food Chemistry, 46, 4372-4375. https://doi.org/10.1021/jf980198v

[39] Gimeno, O., Astiasarán, I. and Bello, J. (2001) Influence of Partial Replacement of $\mathrm{NaCl}$ with $\mathrm{KCl}$ and $\mathrm{CaCl}_{2}$ on Microbiological Evolution of Dry Fermented Sausages. Food Microbiology, 18, 329-334.

[40] Ibañez, C., Quintanilla, L., Cid, C., Astiasaran, I. and Bello, J. (1996) Dry Fermented Sausages Elaborated with Lactobacillus plantarum-Staphylococcus carnosus. Part I: Effect of Partial Replacement of $\mathrm{NaCl}$ with $\mathrm{KCl}$ on the Stability and the Nitrosation Process. Meat Science, 44, 227-234.

[41] Ibañez, C., Quintanilla, L., Cid, C., Astiasarán, I. and Bello, J. (1997) Dry Fermented Sausages Elaborated with Lactobacillus plantarum-Staphylococcus carnosus. Part II: Effect of Partial Replacement of $\mathrm{NaCl}$ with $\mathrm{KCl}$ on the Proteolytic and Insolubilization Processes. Meat Science, 46, 277-284.

[42] Aliño, M., Grau, R., Fuentes, A. and Barat, J.M. (2010) Influence of Low-Sodium Mixtures of Salts on the Post-Salting Stage of Dry-Cured Ham Process. Journal of Food Engineering, 99, 198-205.

[43] Blesa, E., Alino, M., Barat, J.M., Grau, R., Toldra, F. and Pagan, M.J. (2008) Microbiology and Physico-Chemical Changes of Dry-Cured Ham during the Post-Salting Stage as Affected by Partial Replacement of $\mathrm{NaCl}$ by Other Salts. Meat Science, 78, 135-142.

[44] Armenteros, M., Aristoy, M.C., Barat, J.M. and Toldra, F. (2012) Biochemical and Sensory Changes in Dry-Cured Ham Salted with Partial Replacements of $\mathrm{NaCl}$ by Other Chloride Salts. Meat Science, 90, 361-367.

[45] Fulladosa, E., Serra, X., Gou, P. and Arnau, J. (2009) Effects of Potassium Lactate and High Pressure on Transglutaminase Restructured Dry-Cured Hams with Reduced Salt Content. Meat Science, 82, 213-218.

[46] Campagnol, P.C., dos Santos, B.A., Terra, N.N. and Pollonio, M.A.R. (2012) Lysine, 
Disodium Guanylate and Disodium Inosinate as Flavor Enhancers in Low-Sodium Fermented Sausages. Meat Science, 91, 334-338.

[47] Campagnol, P.C.B., dos Santos, B.A., Wagner, R., Terra, N.N. and Pollonio, M.A.R. (2011) The Effect of Yeast Extract Addition on Quality of Fermented Sausages at Low NaCl Content. Meat Science, 87, 290-298.

[48] Corral, S., Salvador, A., Belloch, C. and Flores, M. (2014) Effect of Fat and Salt Reduction on the Sensory Quality of Slow Fermented Sausages Inoculated with Debaryomyces hansenii Yeast. Food Control, 45, 1-7.

[49] Corral, S., Salvador, A., Belloch, C. and Flores, M. (2015) Improvement the Aroma of Reduced Fat and Salt Fermented Sausages by Debaromyces hansenii Inoculation. Food Control, 47, 526-535.

[50] Flores, M., Corral, S., Cano-García, L., Salvador, A. and Belloch, C. (2015) Yeast Strains as Potential Aroma Enhancers in Dry Fermented Sausages. International Journal of Food Microbiology, 212, 16-24.

[51] Corral, S., Belloch, C., López-Díez, J.J., Salvador, A. and Flores, M. (2017) Yeast Inoculation as a Strategy to Improve the Physico-Chemical and Sensory Properties of Reduced Salt Fermented Sausages Produced with Entire Male Fat. Meat Science, 123, 1-7.

[52] Rama, R., Chiu, N., Da Silva, M.S., Hewson, L., Hort, J. and Fisk, I.D. (2013) Impact of Salt Crystal Size on In-Mouth Delivery of Sodium and Saltiness Perception from Snack Foods. Journal of Texture Studies, 44, 338-345. https://doi.org/10.1111/jtxs.12017

[53] Iranpour, J., Clerjon, S., Morrot, G., Claise, B., Jean, B., Thomas-Danguin, T. and Bonny, J.-M. (2014) How Is Salt Taste Intensity Encoded within the Human Brain? The Responses of BOLD fMRI using Food Models. Proceedings of the 12 th International Conference on the Applications of Magnetic Resonance in Food Science: De fining Food by Magnetic Resonance, Cesena, 20-23 May 2014.

[54] Lawrence, G., Salles, C., Septier, C., Busch, J. and Thomas-Danguin, T. (2009) Odour-Taste Interactions: A Way to Enhance Saltiness in Low-Salt Content Solutions. Food Quality and Preference, 20, 241-248.

[55] Lawrence, G., Salles, C., Palicki, O., Septier, C., Busch, J. and Thomas-Danguin, T. (2011) Using Cross-Modal Interactions to Counterbalance Salt Reduction in Solid Foods. International Dairy Journal, 21, 103-110.

[56] Syarifuddin, A., Septier, C., Salles, C. and Thomas-Danguin, T. (2016) Reducing Salt and Fat while Maintaining Taste: An Approach on a Model Food System. Food Quality and Preference, 48, 59-69.

[57] Simopoulos, A.P. (2002) The Importance of the Ratio of Omega-6/Omega-3 Essential Fatty Acids. Biomedicine and Pharmacotherapy, 56, 365-379. https://doi.org/10.1016/S0753-3322(02)00253-6

[58] Olivares, A., Navarro, J.L. and Flores, M. (2011) Effect of Fat Content on Aroma Generation during Processing of Dry Fermented Sausages. Meat Science, 87, 264273.

[59] Olivares, A., Navarro, J.L., Salvador, A. and Flores, M. (2010) Sensory Acceptability of Slow Fermented Sausages Based on Fat Content and Ripening Time. Meat Science, 86, 251-257.

[60] Lorenzo, J.M. and Franco, D. (2012) Fat Effect on Physico-Chemical, Microbial and Textural Changes through the Manufactured of Dry-Cured Foal Sausage Lipolysis, Proteolysis and Sensory Properties. Meat Science, 92, 704-714.

[61] Campagnol, P.C., dos Santos, B.A., Wagner, R., Terra, N.N. and Pollonio, M.A.R. 
(2012) Amorphous Cellulose Gel as a Fat Substitute in Fermented Sausages. Meat Science, 90, 36-42.

[62] Ruiz-Capillas, C., Triki, M., Herrero, A.M., Rodriguez-Salas, L. and Jimenez-Colmenero, F. (2012) Konjac Gel as Pork Backfat Replacer in Dry Fermented Sausages: Processing and Quality Characteristics. Meat Science, 92, 144-150.

[63] Alejandre, M., Poyato, C., Ansorena, D. and Astiasarán, I. (2016) Linseed Oil Gelled Emulsion: A Successful Fat Replacer in Dry Fermented Sausages. Meat Science, 121, 107-113.

[64] Garcia, M.L., Dominguez, R., Galvez, M.D., Casas, C. and Selgas, M.D. (2002) Utilization of Cereal and Fruit Fibres in Low Fat Dry Fermented Sausages. Meat Science, 60, 227-236.

[65] Fernandez-Lopez, J., Sendra, E., Sayas-Barbera, E., Navarro, C. and Perez-Alvarez, J.A. (2008) Physico-Chemical and Microbiological Profiles of "Salchichon" (Spanish Dry-Fermented Sausage) Enriched with Orange Fiber. Meat Science, 80, 410-417.

[66] Aleson-Carbonell, L., Fernández-López, J., Sendra, E., Sayas-Barberá, E. and PérezAlvarez, J.A. (2004) Quality Characteristics of a Non-Fermented Dry-Cured Sausage Formulated with Lemon Albedo. Journal of the Science of Food and Agriculture, 84, 2077-2084. https://doi.org/10.1002/jsfa.1912

[67] Mendoza, E., García, M.L., Casas, C. and Selgas, M.D. (2001) Inulin as Fat Substitute in Low Fat, Dry Fermented Sausages. Meat Science, 57, 387-393.

[68] Eim, V.S., Simal, S., Rossello, C. and Femenia, A. (2008) Effects of Addition of Carrot Dietary Fibre on the Ripening Process of a Dry Fermented Sausage (Sobrassada). Meat Science, 80, 173-182.

[69] Eim, V.S., Simal, S., Rosselló, C., Femenia, A. and Bon, J. (2013) Optimisation of the Addition of Carrot Dietary Fibre to a Dry Fermented Sausage (Sobrassada) Using Artificial Neural Networks. Meat Science, 94, 341-348.

[70] Sánchez-Zapata, E., Díaz-Vela, J., Pérez-Chabela, M.L., Pérez-Alvarez, J.A. and Fernández-Lopez, J. (2013) Evaluation of the Effect of Tiger Nut Fibre as a Carrier of Unsaturated Fatty Acids Rich Oil on the Quality of Dry-Cured Sausages. Food and Bioprocess Technology, 6, 1181-1190. https://doi.org/10.1007/s11947-011-0733-1

[71] Salazar, P., García, M.L. and Selgas, M.D. (2009) Short-Chain Fructooligosaccharides as Potential Functional Ingredient in Dry Fermented Sausages with Different Fat Levels. International Journal of Food Science and Technology, 44, 1100-1107. https://doi.org/10.1111/j.1365-2621.2009.01923.x

[72] Ansorena, D. and Astiasarán, I. (2004) The Use of Linseed Oil Improves Nutritional Quality of the Lipid Fraction of Dry-Fermented Sausages. Food Chemistry, 87, 69-74.

[73] Muguerza, E., Fista, G., Ansorena, D., Astiasaran, I. and Bloukas, J.G. (2002) Effect of Fat Level and Partial Replacement of Pork Backfat with Olive Oil on Processing and Quality Characteristics of Fermented Sausages. Meat Science, 61, 397-404.

[74] Utrilla, M.C., García Ruiz, A. and Soriano, A. (2014) Effect of Partial Replacement of Pork Meat with an Olive Oil Organogel on the Physicochemical and Sensory Quality of Dry-Ripened Venison Sausages. Meat Science, 97, 575-582.

[75] Muguerza, E., Ansorena, D. and Astiasarán, I. (2003) Improvement of Nutritional Properties of Chorizo de Pamplona by Replacement of Pork Backfat with Soy Oil. Meat Science, 65, 1361-1367.

[76] Valencia, I., Ansorena, D. and Astiasaran, I. (2006) Stability of Linseed Oil and Antioxidants Containing Dry Dermented Sausages: A Study of the Lipid Fraction dur- 
ing Different Storage Conditions. Meat Science, 73, 269-277.

[77] Josquin, N.M., Linssen, J.P. and Houben, J.H. (2012) Quality Characteristics of Dutch-Style Fermented Sausages Manufactured with Partial Replacement of Pork Back-Fat with Pure, Pre-Emulsified or Encapsulated Fish Oil. Meat Science, 90, 8186.

[78] Valencia, I., Ansorena, D. and Astiasarán, I. (2007) Development of Dry Fermented Sausages Rich in Docosahexaenoic Acid with Oil from the Microalgae Schizochytrium sp.: Influence on Nutritional Properties, Sensorial Quality and Oxidation Stability. Food Chemistry, 104, 1087-1096.

[79] Lorenzo, J.M., Sichetti-Munekata, P.E., Pateiro, M., Campagnol, P.C.B. and Domínguez, R. (2016) Healthy Spanish Salchichón Enriched with Encapsulated n-3 Long Chain Fatty Acids in Konjac Glucomannan Matrix. Food Research International, 89, 289-295.

[80] Jiménez-Colmenero, F., Triki, M., Herrero, A.M., Rodríguez-Salas, L. and RuizCapillas, C. (2013) Healthy Oil Combination Stabilized in a Konjac Matrix as Pork Fat Replacement in Low-Fat, PUFA-Enriched, Dry Fermented Sausages. LWTFood Science and Technology, 51, 158-163.

[81] Muguerza, E., Gimeno, O., Ansorena, D. and Astiasarán, I. (2004) New Formulations for Healthier Dry Fermented Sausages: A Review. Trends in Food Science and Technology, 15, 452-457.

[82] Garcia-Iniguez de Ciriano, M.G., Garcia-Herreros, C., Larequi, E., Valencia, I., Ansorena, D. and Astiasaran, I. (2009) Use of Natural Antioxidants from Lyophilized Water Extracts of Borago officinalis in Dry Fermented Sausages Enriched in Omega-3 PUFA. Meat Science, 83, 271-277.

[83] Bozkurt, H. (2007) Comparison of the Effects of Sesame and Thymbra spicata Oil during the Manufacturing of Turkish Dry-Fermented Sausage. Food Control, 18, 149-156.

[84] Ba, H.V., Seo, H.W., Cho, S.H., Kim, Y.S., Kim, J.H., Ham, J.S., Park, B.Y. and Nam, S.P. (2016) Antioxidant and Anti-Foodborne Bacteria Activities of Shiitake ByProduct Extract in Fermented Sausages. Food Control, 70, 201-209.

[85] Calvo, M.M., Garcia, M.L. and Selgas, M.D. (2008) Dry Fermented Sausages Enriched with Lycopene from Tomato Peel. Meat Science, 80, 167-172.

[86] Dabin, E. and Jussiaux, R. (1994) Dry-Fermented Sausage. Erti Editeur, Paris. (In French)

[87] Sebranek, J.G. and Bacus, J.N. (2007) Cured Meat Products without Direct Addition of Nitrate or Nitrite: What Are the Issues? Meat Science, 77, 136-147.

[88] Honikel, K.O. (2008) The Use and Control of Nitrate and Nitrite for the Processing of Meat Products. Meat Science, 78, 68-76.

[89] Fraser, P., Chilvers, C., Beral, V. and Hill, M.J. (1980) Nitrate and Human Cancer: A Review of the Evidence. International Journal of Epidemiology, 9, 3-12. https://doi.org/10.1093/ije/9.1.3

[90] Jakszyn, P. and Gonzalez, C. (2006) Nitrosamine and Related Food Intake and Gastric and Oesophageal Cancer Risk: A Systematic Review of the Epidemiological Evidence. World Journal of Gastroenterology, 12, 4296-4303. https://doi.org/10.3748/wjg.v12.i27.4296

[91] Hsu, J., Arcot, J. and Lee, N.A. (2009) Nitrate and Nitrite Quantification from Cured Meat and Vegetables and their Estimated Dietary Intake in Australians. Food Chemistry, 115, 334-339.

[92] Duncan, C., Li, H., Dykhuizen, R., Frazer, R., Johnston, P., MacKnight, G., Smith, 
L., Lamza, K., McKenzie, H., Batt, L., Kelly, D., Golden, M., Benjamin, N. and Leifert, C. (1997) Protection against Oral and Gastrointestinal Diseases: Importance of Dietary Nitrate Intake, Oral Nitrate Reduction and Enterosalivary Nitrate Circulation. Comparative Biochemistry and Physiology Part A: Physiology, 118, 939-948.

[93] Bartsch, H., Ohshima, H., Shuker, D.E.G., Pignatelli, B. and Calmels, S. (1990) Exposure of Humans to Endogenous N-Nitroso Compounds: Implications in Cancer Etiology. Mutation Research/ Reviews in Genetic Toxicology, 238, 255-267.

[94] Joossens, J.V., Hill, M.J., Elliott, P., Stamler, R., Stamler, J., Lesaffre, E., Dyer, A., Nichols, R., Kesteloot, H. and on behalf of European Cancer Prevention (ECP) and the Intersalt Cooperative Research Group (1996) Dietary Salt, Nitrate and Stomach Cancer Mortality in 24 Countries. International Journal of Epidemiology, 25, 494504. https://doi.org/10.1093/ije/25.3.494

[95] Jiménez-Colmenero, F., Carballo, J. and Cofrades, S. (2001) Healthier Meat and Meat Products: Their Role as Functional Foods. Meat Science, 59, 5-13.

[96] Pichner, R., Hechelmann, H, Steinrueck, H. and Gareis, M. (2006) ShigatoxinProducing Escherichia Coli (STEC) in Conventionally and Organically Produced Salami Products. Fleischwirtschaft, 86, 112-114.

[97] Hospital, X.F., Hierro, E. and Fernández, M. (2014) Effect of Reducing Nitrate and Nitrite Added to Dry Fermented Sausages on the Survival of Salmonella typhimurium. Food Research International, 62, 410-415.

[98] Tsoukalas, D.S., Katsanidis, E., Marantidou, S. and Bloukas, J.G. (2011) Effect of Freeze-Dried Leek Powder (FDLP) and Nitrite Level on Processing and Quality Characteristics of Fermented Sausages. Meat Science, 87, 140-145.

[99] Schlüchter, S., Eberhard, P., Kneubühler, H. and Hadorn, R.S (2010) Manufacture of Dry-Fermented Sausages Containing Different Levels of Nitrate of Natural or Synthetic Origin. Viandes \& Produits Carnés, 28, 3-7. (In French)

[100] Toldrá, F. and Reig, M. (2011) Innovations for Healthier Processed Meats. Trends in Food Science and Technology, 22, 517-522.

[101] Wakamatsu, J., Nishimura, T. and Hattori, A. (2004) A Zn-Porphyrin Complex Contributes to Bright Red Color in Parma Ham. Meat Science, 67, 95-100.

[102] Benedini, R., Raja, V. and Parolari, G. (2008) Zinc-Protoporphyrin IX Promoting Activity in Pork Muscle. LWT-Food Science and Technology, 41, 1160-1166.

[103] Wakamatsu, J., Okui, J., Hayashi, N., Nishimura, T. and Hattori, A. (2007) Zn Protoporphyrin IX Is Formed Not from Heme but from Protoporphyrin IX. Meat Science, 77, 580-586.

[104] Wakamatsu, J., Hayashi, N., Nishimura, T. and Hattori, A. (2010) Nitric Oxide Inhibits the Formation of Zinc Protoporphyrin IX and Protoporphyrin IX. Meat Science, 84, 125-128.

[105] Adamsen, C.E., Moller, J.K., Laursen, K., Olsen, K. and Skibsted, L.H. (2006) ZnPorphyrin Formation in Cured Meat Products: Effect of Added Salt and Nitrite. Meat Science, 72, 672-679.

[106] Hammes, W.P. (2012) Metabolism of Nitrate in Fermented Meats: The Characteristic Feature of a Specific Group of Fermented Foods. Food Microbiology, 29, 151156.

[107] Lundberg, J.O., Carlstrom, M., Larsen, F.J. and Weitzberg, E. (2011) Roles of Dietary Inorganic Nitrate in Cardiovascular Health and Disease. Cardiovascular Research, 89, 525-532. https://doi.org/10.1093/cvr/cvq325

[108] Milkowski, A., Garg, H.K., Coughlin, J.R. and Bryan, N.S. (2010) Nutritional Epidemiology in the Context of Nitric Oxide Biology: A Risk-Benefit Evaluation for 
Dietary Nitrite and Nitrate. Nitric Oxide, 22, 110-119.

[109] Parthasarathy, D.K. and Bryan, N.S. (2012) Sodium Nitrite: the "Cure" for Nitric Oxide Insufficiency. Meat Science, 92, 274-279.

[110] Klingberg, T.D., Axelsson, L., Naterstad, K., Elsser, D. and Budde, B.B. (2005) Identification of Potential Probiotic Starter Cultures for Scandinavian-Type Fermented Sausages. International Journal of Food Microbiology, 105, 419-431.

[111] Muthukumarasamy, P. and Holley, R.A. (2006) Microbiological and Sensory Quality of Dry Fermented Sausages Containing Alginate-Microencapsulated Lactobacillus reuteri. International Journal of Food Microbiology, 111, 164-169.

[112] De Vuyst, L.D., Falony, G. and Leroy, F. (2008) Probiotics in Fermented Sausages. Meat Science, 80, 75-78.

[113] Drosinos, E. (2012) Effective Strategies towards Healthier Fermented Meat Products. Agro Food Industry Hi-Tech, 23, 42-45.

[114] Jiménez-Colmenero, F. (2007) Healthier Lipid Formulation Approaches in MeatBased Functional Foods. Technological Options for Replacement of Meat Fats by Non-Meat Fats. Trends in Food Science and Technology, 18, 567-578.

[115] O’Shea, N., Arendt, E.K. and Gallagher, E. (2012) Dietary Fibre and Phytochemical Characteristics of Fruit and Vegetable By-Products and Their Recent Applications as Novel Ingredients in Food Products. Innovative Food Science and Emerging Technologies, 16, 1-10.

[116] Zhang, W., Xiao, S., Samaraweera, H., Lee, E.J. and Ahn, D.U. (2010) Improving Functional Value of Meat Products. Meat Science, 86, 15-31.

[117] Beriain, M.J., Gomez, I., Petri, E., Insausti, K. and Sarries, M.V. (2011) The Effects of Olive Oil Emulsified Alginate on the Physico-Chemical, Sensory, Microbial and Fatty Acid Profiles of Low-Salt, Inulin-Enriched Sausages. Meat Science, 88, 189197.

[118] Safa, H., Gatellier, P., Lebert, A., Picgirard, L. and Mirade, P.S. (2015) Effect of Combined Salt and Animal Fat Reductions on Physicochemical and Biochemical Changes during the Manufacture of Dry-Fermented Sausages. Food and Bioprocess Technology, 8, 2109-2122. https://doi.org/10.1007/s11947-015-1563-3

[119] Safa, H., Gatellier, P., Berdagué, J.L., Kondjoyan, N., Mercier, F., Portanguen, S., Favier, R. and Mirade, P.S. (2016) Physicochemical, Biochemical and Instrumental Attributes and Consumer Acceptability of Dry-Fermented Sausages Elaborated with Combined Partial Substitutions of Sodium Chloride and Pork Backfat. Food and Nutrition Sciences, 7, 1297-1314. https://doi.org/10.4236/fns.2016.714119

[120] Mora-Gallego, H., Guàrdia, M.D., Serra, X., Gou, P. and Arnau, J. (2016) Sensory Characterization and Consumer Acceptability of Potassium Chloride and Sunflower Oil Addition in Small-Caliber Non-Acid Fermented Sausages with a Reduced Content of Sodium Chloride and Fat. Meat Science, 112, 9-15.

[121] Fulladosa, E., Santos-Garcés, E., Picouet, P. and Gou, P. (2010) Prediction of Salt and Water Content in Dry-Cured Hams by Computed Tomography. Journal of Food Engineering, 96, 80-85.

[122] Santos-Garcés, E., Gou, P., Garcia-Gil, N., Arnau, J. and Fulladosa, E. (2010) NonDestructive Analysis of $\mathrm{a}_{\mathrm{w}}$, Salt and Water in Dry-Cured Hams during Drying Process by Means of Computed Tomography. Journal of Food Engineering, 101, 187-192.

[123] Santos-Garces, E., Munoz, I., Gou, P., Sala, X. and Fulladosa, E. (2012) Tools for Studying Dry-Cured Ham Processing by Using Computed Tomography. Journal of Agricultural and Food Chemistry, 60, 241-249. https://doi.org/10.1021/jf203213q 
[124] Aburto, N.J., Hanson, S., Gutierrez, H., Hooper, L., Elliott, P. and Cappuccio, F.P. (2013) Effect of Increased Potassium Intake on Cardiovascular Risk Factors and Disease: Systematic Review and Meta-Analyses. British Medical Journal, 346, f1378. https://doi.org/10.1136/bmj.f1378

[125] Castro, H. and Raij, L. (2013) Potassium in Hypertension and Cardiovascular Disease. Seminars in Nephrology, 33, 277-289. https://doi.org/10.1016/j.semnephrol.2013.04.008

[126] Gimeno, O., Astiasarán, I. and Bello, J. (2001) Calcium Ascorbate as a Potential Partial Substitute for $\mathrm{NaCl}$ in Dry Fermented Sausages: Effect on Colour, Texture and Hygienic Quality at Different Concentrations. Meat Science, 57, 23-29.

[127] Corpet, D.E. (2011) Red Meat and Colon Cancer: Should We Become Vegetarians, or Can We Make Meat Safer? Meat Science, 89, 310-316.

[128] Pierre, F., Santarelli, R., Tache, S., Gueraud, F. and Corpet, D.E. (2008) Beef Meat Promotion of Dimethylhydrazine-Induced Colorectal Carcinogenesis Biomarkers Is Suppressed by Dietary Calcium. British Journal of Nutrition, 99, 1000-1006. https://doi.org/10.1017/S0007114507843558

[129] Chizzolini, R., Zanardi, E., Dorigoni, V. and Ghidini, S. (1999) Calorific Value and Cholesterol Content of Normal and Low-Fat Meat and Meat Products. Trends in Food Science and Technology, 10, 119-128.

[130] Guardia, M.D., Guerrero, L., Gelabert, J., Gou, P. and Arnau, J. (2006) Consumer Attitude towards Sodium Reduction in Meat Products and Acceptability of Fermented Sausages with Reduced Sodium Content. Meat Science, 73, 484-490.

[131] Harkouss, R., Chevarin, C., Daudin, J.D. and Mirade, P.S. (2014) Development of a "Numerical Ham" Model that Couples Water and Salt Transfers to Proteolysis during the Dry-Cured Ham Process. Proceedings of the 13 th International Conference on Modelling and Applied Simulation, Bordeaux, 10-12 September 2014, 65-70.

Submit or recommend next manuscript to SCIRP and we will provide best service for you:

Accepting pre-submission inquiries through Email, Facebook, LinkedIn, Twitter, etc. A wide selection of journals (inclusive of 9 subjects, more than 200 journals)

Providing 24-hour high-quality service

User-friendly online submission system

Fair and swift peer-review system

Efficient typesetting and proofreading procedure

Display of the result of downloads and visits, as well as the number of cited articles

Maximum dissemination of your research work

Submit your manuscript at: http://papersubmission.scirp.org/

Or contact fns@scirp.org 